\title{
Genetic and histopathological analysis of a case of primary intraosseous carcinoma, NOS with features of both ameloblastic carcinoma and squamous cell carcinoma
}

Akane Yukimori $^{1,2}$, Maiko Tsuchiya ${ }^{3}$, Akane Wada $^{1}$, Yasuyuki Michi ${ }^{4}$, Kou Kayamori ${ }^{3}$, Kei Sakamoto ${ }^{3}$ and Tohru Ikeda ${ }^{3^{*}}$ (1)

\begin{abstract}
Background: Primary intraosseous carcinoma (PIOC), NOS is an odontogenic carcinoma with unknown etiology. Its diagnosis may be used when central jaw carcinoma cannot be categorized as any other type of carcinoma. Further information on this extremely rare tumor is needed to improve our understanding and evaluate the classification of odontogenic carcinomas.

Case presentation: We herein presented two patients with PIOC, NOS with different clinical and histopathological features and analyzed gene mutations in these patients using next-generation sequencing (NGS). The typical PIOC, NOS case had many histopathological similarities to oral squamous cell carcinoma (OSCC), including the missense point mutations of TP53 Glu285Val, KDR Gln472His, and APC Pro1433Leu, which are similar to those in other cancers; however, no mutations were detected in the other patient with an atypical presentation of PIOC, NOS, which was derived from a precursor cystic lesion with similarities to both ameloblastic carcinoma and OSCC.
\end{abstract}

Conclusions: Genetic analysis suggested that these two PIOC, NOS cases have different features and can be subcategorized.

Keywords: Ameloblastoma, Intraosseous carcinoma, Malignant tumor, Next-generation sequencing, Odontogenic carcinoma

\section{Background}

As described in the WHO Classification of Head and Neck Tumors, primary intraosseous carcinoma (PIOC), NOS is a central jaw carcinoma that cannot be categorized as any other type of carcinoma. PIOC, NOS is assumed to arise from odontogenic epithelium. Some cases arise from odontogenic cysts or other benign precursors. Most lesions are squamous and composed of

\footnotetext{
* Correspondence: tohrupth.mpa@tmd.ac.jp

${ }^{3}$ Department of Oral Pathology, Graduate School of Medical and Dental Sciences, Tokyo Medical and Dental University, 1-5-45 Yushima, Bunkyo-ku, Tokyo 113-8549, Japan

Full list of author information is available at the end of the article
}

islands or small nests of a neoplastic squamous epithelium [1]. This type of tumor was described as primary intraosseous squamous cell carcinoma in previous editions of the WHO classification and was further classified into three subtypes: solid type, derived from keratocystic odontogenic tumors, and derived from odontogenic cysts [2]. The previous classification strongly suggested that primary intraosseous squamous cell carcinoma comprises intragnathic tumors derived from multiple origins, and genetic information needs to be applied in addition to histopathological findings to evaluate the classification of PIOC, NOS. 
Recent studies using next-generation sequencing (NGS) revealed several gene mutations in odontogenic tumors, including ameloblastoma [3]; however, mutations in PIOC, NOS remain unclear because of the low incidence of this tumor. We herein report two patients with PIOC, NOS with varying histopathological features. We also analyzed genetic mutations in these patients using NGS and compared their genetic and histopathological features.

\section{Case presentation}

\section{Case 1}

A 28-year-old Japanese male presented with a swelling of his left mandible visited our hospital. He was a nonsmoker and had dull pain in the left molar region of the mandible. A clinical examination revealed slight facial asymmetry and an elastic hard mass in the left molar region. The presence of a multilocular radiolucent lesion was observed in the left lateral incisor to the mandibular condyle area (Fig. 1), and the clinical diagnosis was an ameloblastoma or a keratocystic odontogenic tumor (current name for an odontogenic keratocyst). A biopsy was performed, and the histopathological diagnosis was a cystic lesion suggestive of a keratocystic odontogenic tumor (Fig. 2a). After fenestration, the patient was assessed to evaluate the prognosis of the condition at 1 year and 3 months, and surgical enucleation of the lesion was performed. The histopathology of the surgical enucleation specimen revealed an odontogenic keratocyst-like lesion in most parts (Fig. 2b). In a small portion, the cyst-like lesion had peripheral palisaded columnar cells with hyperchromatic nuclei, but apparent stellate reticulum-like cells were not seen (Fig. 2c); a diagnosis of an odontogenic tumor suggestive of an ameloblastoma was made. Five months after surgery, recurrence was clinically suggested, a biopsy was performed, and the diagnosis of recurrence of ameloblastoma was made. The lesion was enucleated, and the histopathology of the enucleated specimen revealed large nests or sheets of tumor cells. The morphology of this tumor was composed of an ameloblastoma-like lesion and an oral squamous cell

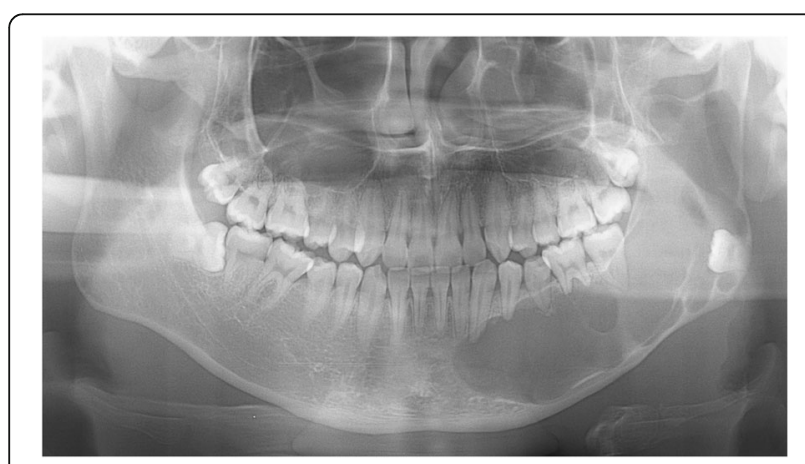

Fig. 1 Panorama $X$-ray photograph of case 1 at the first visit. Multilocular radiolucent lesions in the left mandibular region carcinoma (OSCC)-like lesion. In the ameloblastoma-like lesion, peripheral cells were columnar with hyperchromatic nuclei arranged in a palisading pattern (Fig. 2d). Nuclear atypia and some mitotic figures were evident in both an ameloblastoma-like lesion (Fig. 2e) and an OSCC-like lesion (Fig. 2f). No relationship to the oral mucosa was noted. The Ki-67 labeling index in the OSCC-like lesion was $20 \%$ (Fig. $2 \mathrm{~g}, \mathrm{~h}$ ). Based on these findings, this tumor was considered to be an intraosseous odontogenic carcinoma derived from a precursor odontogenic keratocyst. The histopathological findings revealed characteristics of both type 1 (PIOC arising from an odontogenic cyst) and type 2B (ameloblastic carcinoma arising de novo from an ameloblastoma or odontogenic cyst) of the widely accepted Waldron and Mustoe's traditional classification of odontogenic carcinoma [4]. Considering the atypical histopathological views of the tumor, we chose a diagnosis of exclusion, and the final diagnosis was primary intraosseous carcinoma (PIOC) with features of type 1 and type $2 \mathrm{~B}$ as a primary intraosseous carcinoma, NOS rather than an ameloblastic carcinoma, based on the definition of the current WHO Classification of PIOC, NOS [1]. Two years and 6 months after surgery, the patient had survived without recurrence.

\section{Case 2}

A 67-year-old Japanese male presented with mobility of the front teeth and occlusal pain. He had a smoking history of 10 cigarettes a day for 47 years. Radiologically, the tumor showed marked bone resorption with progression into the left incisor region to the mandibular ramus (Fig. 3). The tumor involved the inner pterygoid and masseter muscles, and the clinical diagnosis was a malignant tumor of the mandible. Biopsy of the region was performed, and a histopathological diagnosis of squamous cell carcinoma was made. Therefore, hemimandibulectomy was performed. After surgery, postoperative chemoradiotherapy (administration of S-1 [tegafur/gimeracil/oteracil] and 60 Gy irradiation) was performed. The surgical specimen showed islands or small nests of a neoplastic squamous epithelium with mild keratinization (Fig. 4a). Nuclear atypia and pleomorphism were evident, and a high Ki-67 labeling index (40\%) was noted (Fig. 4b). The lesion was intraosseous and there were no connections between the tumor and oral mucosa. The histopathology of this tumor was similar to that of OSCC. Based on the findings of the central jaw squamous cell carcinoma isolated from the oral mucosa, a final diagnosis of PIOC, NOS was made. Three years after surgery, the patient had survived without recurrence.

\section{NGS}

We analyzed mutations in hotspot regions in 50 genes commonly associated with cancer by targeted NGS in 

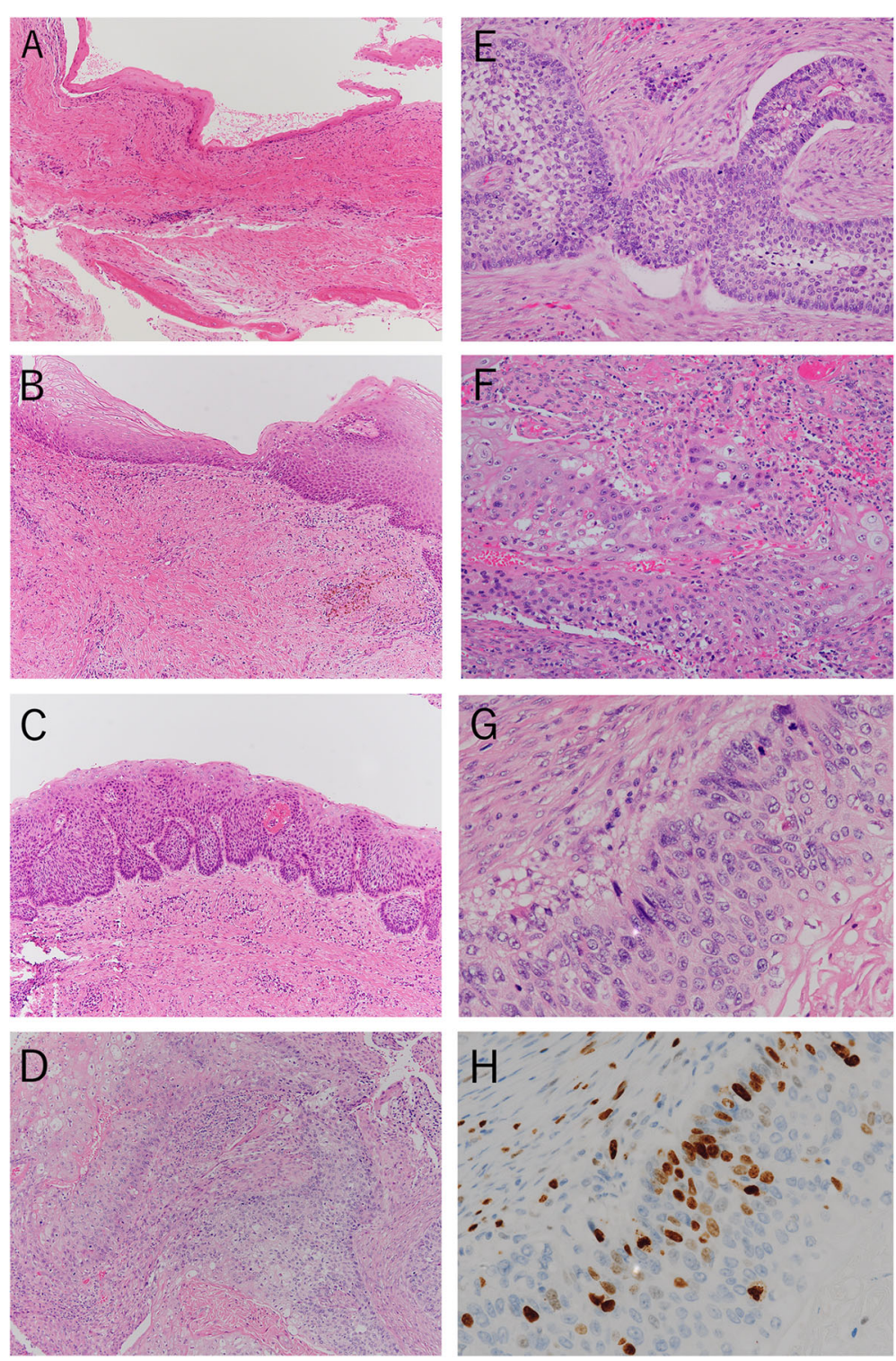

Fig. 2 The transition of histopathological findings of case 1. a A cystic lesion in the biopsy specimen at the first visit of the patient (hematoxylin \& eosin [H\&E] staining, original magnification $\times 100$ ). b A cystic lesion in the enucleated specimen after fenestration (H\&E staining, original magnification $\times 100$ ). $\mathbf{c}$ A cystic lesion in the enucleated specimen with ameloblastoma-like findings after fenestration (H\&E staining, original magnification $\times 100$ ). $\mathbf{d}$ Tumor infiltration in the enucleated specimen of the recurrent lesion (H\&E staining, original magnification $\times 100)$. e An ameloblastoma-like lesion in the enucleated specimen of the recurrent lesion (H\&E staining, original magnification $\times 200$ ). $\mathbf{f}$ An OSCC-like lesion in the enucleated specimen of the recurrent lesion (H\&E staining, original magnification $\times 200$ ). $\mathbf{g}$ High-power magnification of the OSCC-like lesion in the enucleated specimen of the recurrent lesion. The specimen was composed of atypical tumor cells with mitoses (H\&E staining, original magnification $\times 400$ ). $\mathbf{h}$ Immunohistochemistry of the tumor using Ki-67 (original magnification $\times 400$ )

specimens from these two PIOC, NOS patients. In addition, a patient with ameloblastoma (case 3) was used as a control (Fig. 5a, b). We used formalin-fixed-paraffin-embedded specimens collected at Tokyo Medical and Dental University Dental Hospital.

DNA was extracted from $20-\mu \mathrm{m}$-thick sections using the QIAamp DNA FFPE Tissue Kit (Qiagen, Hilden, Germany). Library preparations were performed using the Ion AmpliSeq Library Kit 2.0 and Ion AmpliSeq
Cancer Hotspot Panel v2 (Thermo Fisher Scientific, Waltham, MA, USA). The panel target's hotspot regions included more than 2800 COSMIC mutations of 50 cancer-related genes. After library preparation, each amplicon library was quantified using the Ion Library TaqMan Quantitation Kit (Thermo Fisher Scientific) and sequenced with the Ion Proton platform and Ion 318 Chip Kit v2 (Thermo Fisher Scientific). The average read depths were approximately 770 . 


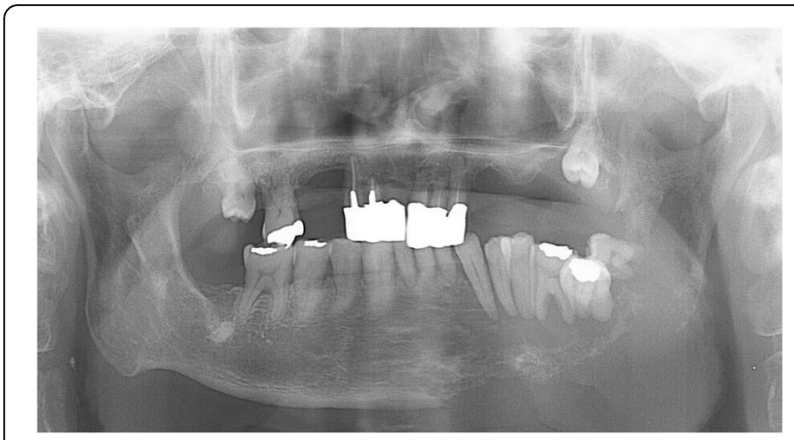

Fig. 3 Panoramic X-ray photograph of case 2 at the first visit. Marked resorption of the left mandibular bone

Data were analyzed using the Torrent Suite Software v4.2.191 (Thermo Fisher Scientific) and Ion Reporter Software v4.6 (Thermo Fisher Scientific). Read alignments were performed using the human reference genome hg19. Candidate pathogenic variants were filtered based on the number of reads in a target sequence and
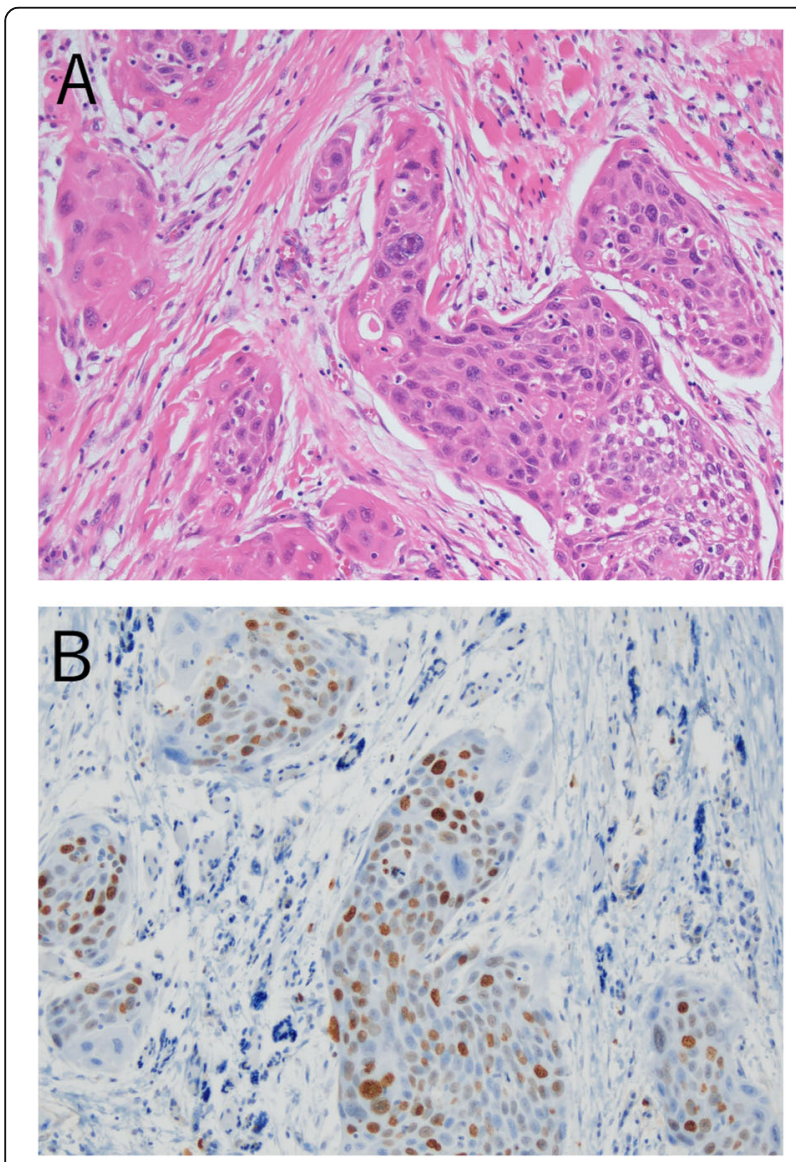

Fig. 4 Histopathological findings of case 2. a Infiltration of tumor nests composed of squamous epithelial cells with atypia (H\&E staining, original magnification $\times 400$ ). $\mathbf{b}$ Immunohistochemistry of the tumor using Ki-67 (original magnification $\times 400$ )
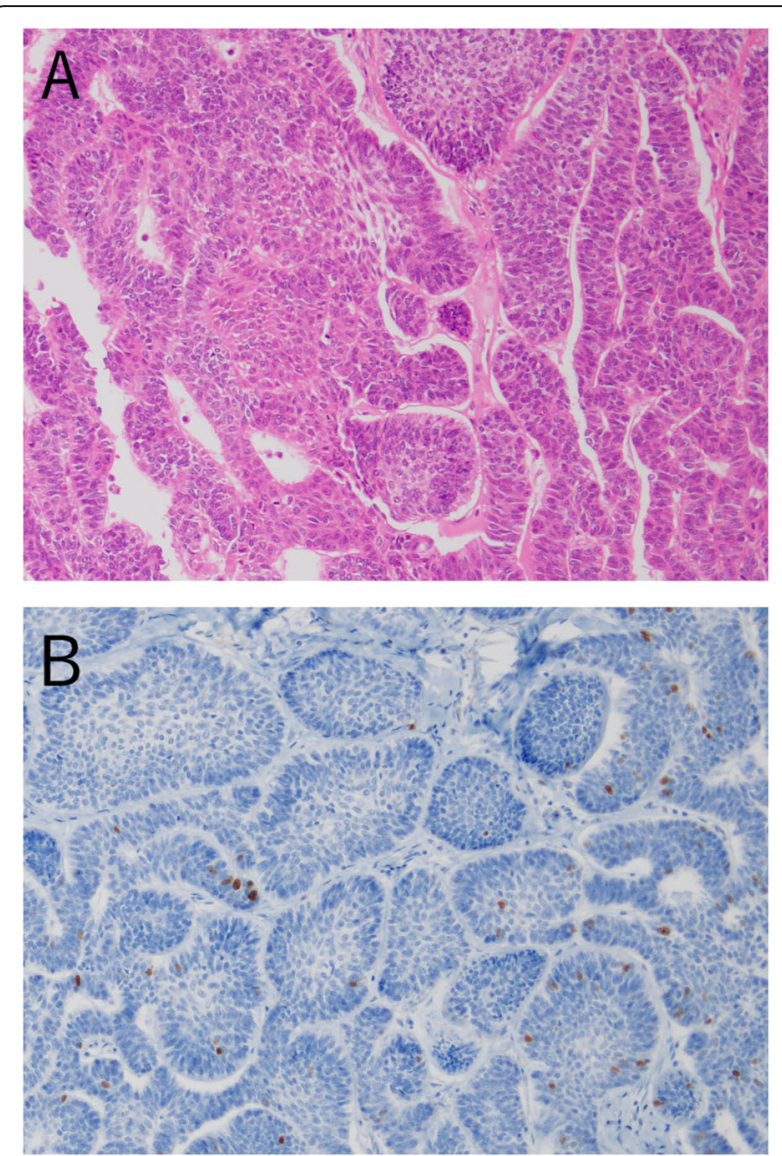

Fig. 5 Histopathological findings of case 3. a Ameloblastoma composed of follicular and plexiform patterns (H\&E staining, original magnification $\times 200$ ). $\mathbf{b}$ Immunohistochemistry of the

ameloblastoma using Ki-67 (original magnification $\times 200$ )

variant frequency in the total number of reads. Intronic, homogeneous, or synonymous variants were excluded. Mutations were analyzed using SIFT, PolyPhen, and MutationTaster and were considered to be relevant when scored as deleterious by at least two of these algorithms.

The NGS results are shown in Table 1 . No mutations were observed in case 1 . In contrast, missense point mutations in TP53 Glu285Val, KDR Gln472His, and APC Pro1433Leu were noted in case 2. The BRAF Val600Glu mutation was found in the patient with ameloblastoma (case 3).

\section{Discussion}

In the present WHO Classification of Head and Neck Tumors published in 2017 [1], odontogenic carcinomas are classified into ameloblastic carcinoma, PIOC, NOS, sclerosing odontogenic carcinoma, clear cell odontogenic carcinoma, and ghost cell odontogenic carcinoma. In contrast to other odontogenic carcinomas, PIOC, 
Table 1 Summary of SNPS analyzed by NGS for the two patients with PIOC, NOS and a patient with ameloblastoma

\begin{tabular}{llll}
\hline Patient no. & 1. PIOC, NOS & 2. PIOC, NOS & 3. Ameloblastoma \\
\hline Age & 28 & 67 & 32 \\
Sex & M & M & M \\
Location & Left mandible & Left mandible & Left mandible \\
Size $(\mathrm{mm})$ & 75 & 35 & 45 \\
SNP in next-generation sequencing & none & TP53 p.Glu285Val (c.854A $>$ T) & BRAF \\
& & KDR p.Gln472His (c.1416A $>$ T) & P.Val600Glu (c.1799T > A) \\
& & APC p.Pro1433Leu (c.4298C $>$ T) & \\
\hline
\end{tabular}

NOS does not have unique morphological features, and the name PIOC, NOS denotes a central jaw odontogenic carcinoma that cannot be categorized into the other odontogenic carcinomas.

The current WHO classification of odontogenic carcinomas added a diagnosis of exclusion, PIOC, NOS. Some PIOC, NOS cases have been shown to derive from different origins and may be further divided into multiple subcategories. Genetic alterations detected by NGS have recently provided valuable information for clarifying the oncogenesis. In the head and neck region, $B R A F$ gene mutations are detected at a high frequency in ameloblastomas $[3,5,6]$, and this was also confirmed not only by genetic analysis but also by immunohistochemistry using a BRAF V600E-mutant specific antibody [7-9]. We recently reported that 10 out of 11 patients with calcifying cystic odontogenic tumors (calcifying odontogenic cyst) have mutations in the CTNNB1 gene, while 12 out of 14 patients with ameloblastoma have mutations in the BRAF gene [10]. We also reported a patient with ghost cell odontogenic carcinoma with a mutation in the CTNNB1 gene, suggesting that CTNNB1 gene mutations are one of the common features of lesions accompanied by ghost cell keratinization [11]. These findings confirmed that genetic alterations not only provide valuable information on oncogenesis but also contribute to the diagnosis and classification of odontogenic lesions. NGS may also contribute to the further study of odontogenic carcinomas; however, the greatest limitation to this research is the rarity of these lesions.

In the present study, we identified two cases of PIOC, NOS with different clinical and histopathological features and compared gene mutations using NGS. Case 1 exhibited features of both ameloblastic carcinoma and OSCC; however, BRAF gene mutations, which are frequently detected in ameloblastoma, were not detected. In addition, no gene mutations were identified using the Ion AmpliSeq Cancer Hotspot Panel v2. To reach a final diagnosis of PIOC, NOS in case 1, we carefully considered a differential diagnosis of ameloblastic carcinoma. Based on histopathological findings without definite features of ameloblastoma or ameloblastic carcinoma in the precursor lesion and the atypical histopathological views of the tumor, we finally chose a diagnosis of exclusion and diagnosed this PIOC with features of type 1 and type $2 \mathrm{~B}$ as PIOC, NOS, following the current WHO classification of odontogenic carcinomas. Although PIOC, NOS includes tumors arising in odontogenic precursor lesions, reports of odontogenic tumors derived from precursor lesions are very limited, and most of them have features of OSCC [1]. Some cases of ameloblastoma arising in the wall of dentigerous cysts have been reported $[12,13]$. Except for dentigerous cysts, only a few cases of ameloblastoma arising in glandular odontogenic cysts have been reported [14]. Case 1 in this study is an extremely rare report of PIOC, NOS with features of both ameloblastic carcinoma and squamous cell carcinoma arising in a precursor cyst. This may also be considered a case of ameloblastic carcinoma arising in a precursor cyst, but the sole histopathological criterion is PIOC, NOS.

Case 1 did not have any gene mutations, whereas case 2, which had features of OSCC, had mutations in the TP53, KDR, and APC genes. TP53 Glu285 Val, which is located in the DNA-binding domain at codon 285 (H2 $\alpha$-helix) of TP53, resulted in a glutamic acid to valine substitution. Russell-Swetek et al. reported that functional analyses of TP53 Glu285Val revealed significant defects in its ability to regulate promoter activity, suppress tumor cell growth, and trigger apoptosis, and TP53 Glu285Val efficiently functions as a dominant negative regulator that neutralizes wild-type p53 activity [15]. TP53 Glu285 Val was reported in a pediatric case of adrenocortical carcinoma and choroid plexus carcinoma [15]. There have been no reports on mutations in OSCC; however, TP53 Arg282Trp was detected in a case of OSCC that was located in the same DNA-binding domain of TP53 Glu285 Val [16]. The KDR gene recognizes vascular endothelial growth factor receptor-2, and the KDR Gln472His mutation has been detected in lung and prostate cancers [17, 18]. APC Pro1433Leu was also detected in renal cell carcinomas [19], and these results suggest that the tumor in case 2 
arose from an odontogenic epithelium by mutations found in other cancers.

We previously reported that BRAF mutations were present in more than $85 \%$ of ameloblastoma cases [10]. Although no definitive data were present, case 1 may have been a tumor other than ameloblastoma, and oncogenesis in this case may have been attributed to mutations other than those in Ion AmpliSeq Cancer Hotspot Panel v2 or to other gene alterations, such as translocations. In contrast, PIOC, NOS, with many morphological similarities to OSCC, has similar gene mutations to OSCC. These results suggest that these two PIOC, NOS cases belong to different subcategories. However, its low incidence leads to difficulties in performing a systematic analysis that includes many cases of these odontogenic carcinomas, which can only be done with a review of the literature [20].

\section{Conclusion}

We reported an extremely rare case of PIOC, NOS with features of both ameloblastic carcinoma and OSCC arising in a precursor cyst and compared this atypical case to a typical case of PIOC, NOS with features of OSCC. The accumulation of data on a small number of cases is essential to improve our understanding of PIOC, NOS, and the present results suggest the importance of obtaining genetic information as well.

\section{Abbreviations}

NGS: Next-generation sequencing; OSCC: Oral squamous cell carcinoma; PIOC: Primary intraosseous carcinoma

\section{Acknowledgements}

Not applicable.

\section{Authors' contributions}

AY was responsible for the data acquisition, analysis of data, and drafting of the manuscript. MT, AW, KK, and KS were resonsible for the pathological diagnosis and analysis and critical revision of the draft. YM was responsible for the clinical data acquisition and critical revision of the draft. TI was responsible for the conception and design of data analysis and drafting of the manuscript. All authors read and approved the final manuscript.

\section{Funding}

Not applicable.

\section{Availability of data and materials}

The datasets used and/or analyzed during the current study are available from the corresponding author upon reasonable request.

\section{Ethics approval and consent to participate}

Ethics approval was obtained from the Ethics Committee of the Faculty of Dentistry, Tokyo Medical and Dental University (Registration No. 1228).

\section{Consent for publication}

Written informed consent was obtained from the patients. Copies of the consent forms are available for review by the Editor of this journal.

\section{Competing interests}

The authors declare that they have no competing interests.

\section{Author details}

'Department of Diagnostic Oral Pathology, Graduate School of Medical and Dental Sciences, Tokyo Medical and Dental University, 1-5-45 Yushima, Bunkyo-ku, Tokyo 113-8549, Japan. ${ }^{2}$ Present Address: Department of Oral Pathology, School of Dentistry, Showa University, 1-5-8 Hatanodai, Shinagawa-ku, Tokyo 142-8555, Japan. ${ }^{3}$ Department of Oral Pathology, Graduate School of Medical and Dental Sciences, Tokyo Medical and Dental University, 1-5-45 Yushima, Bunkyo-ku, Tokyo 113-8549, Japan. ${ }^{4}$ Department of Oral and Maxillofacial Surgery, Graduate School of Medical and Dental Sciences, Tokyo Medical and Dental University, 1-5-45 Yushima, Bunkyo-ku, Tokyo 113-8549, Japan.

Received: 27 November 2019 Accepted: 21 February 2020 Published online: 29 February 2020

\section{References}

1. Odell EW, Muller S, Richardron M. Odontogenic carcinomas. In: El-Naggar AK, JKC C, Grandis JR, Takata T, Lyon SPJ, editors. WHO Classification of Head and Neck Tumours. 4th ed. Lyon: IARC; 2017. p. 206-9.

2. Eversole LR, Siar $\mathrm{CH}$, van der Waal I. Primary intraosseous squamous cell carcinomas. In: Barnes L, Eveson JW, Reichart P, Lyon SD, editors. Pathology and Genetics of Head and Neck Tumours. 3rd ed. Lyon: IARC; 2005. p. 290-1.

3. Sweeney RT, McClary AC, Myers BR, Biscocho J, Neahring L, Kwei KA, Qu K, Gong $\mathrm{X}, \mathrm{Ng} \mathrm{T}$, Jones $\mathrm{CD}$, et al. Identification of recurrent $\mathrm{SMO}$ and BRAF mutations in ameloblastomas. Nat Genet. 2014;46:722-5.

4. Waldron CA, Mustoe TA. Primary intraosseous carcinoma of the mandible with probable origin in an odontogenic cyst. Oral Surg Oral Med Oral Pathol. 1989;67:716-24.

5. Kurppa KJ, Caton J, Morgan PR, Ristimaki A, Ruhin B, Kellokoski J, Elenius K, Heikinheimo K. High frequency of BRAF V600E mutations in ameloblastoma. J Pathol. 2014;232:492-8.

6. Brown NA, Rolland D, McHugh JB, Weigelin HC, Zhao L, Lim MS, ElenitobaJohnson KS, Betz BL. Activating FGFR2-RAS-BRAF mutations in ameloblastoma. Clin Cancer Res. 2014;20:5517-26.

7. Kwon JH, Jeong BK, Yoon YS, Yu CS, Kim J. Utility of BRAF VE1 immunohistochemistry as a screening tool for colorectal cancer harboring BRAF V600E mutation. J Pathol Transl Med. 2018:52:157-63.

8. do Canto AM, BMR d SM, Schussel JL, Wastner BF, Sassi LM, Correa L, de Freitas RR, Hasseus B, Kjeller G, CAL J, Braz-Silva PH. Immunohistochemical analysis of BRAF V600E mutation in ameloblastomas. Clin Oral Investig. 2019;23:779-84.

9. Kuan SF, Navina S, Cressman KL, Pai RK. Immunohistochemical detection of BRAF V600E mutant protein using the VE1 antibody in colorectal carcinoma is highly concordant with molecular testing but requires rigorous antibody optimization. Hum Pathol. 2014;45:464-72.

10. Yukimori A, Oikawa Y, Morita KI, Nguyen CTK, Harada H, Yamaguchi S, Kayamori K, Yamaguchi A, Ikeda T, Sakamoto K. Genetic basis of calcifying cystic odontogenic tumors. PLoS One. 2017;12:e0180224.

11. Ohata Y, Kayamori K, Yukimori A, Sumikura K, Ohsako T, Harada H, Sakamoto $\mathrm{K}$, Ikeda T. A lesion categorized between ghost cell odontogenic carcinoma and dentinogenic ghost cell tumor with CTNNB1 mutation. Pathol Int. 2018; 68:307-12.

12. Bhushan NS, Rao NM, Navatha M, Kumar BK. Ameloblastoma arising from a dentigerous cyst-a case report. J Clin Diagn Res. 2014;8:Zd23-5.

13. Kondamari SK, Taneeru S, Guttikonda VR, Masabattula GK. Ameloblastoma arising in the wall of dentigerous cyst: report of a rare entity. J Oral Maxillofac Pathol. 2018;22:S7-s10.

14. Cousin T, Bobek S, Oda D. Glandular odontogenic cyst associated with ameloblastoma: case report and review of the literature. J Clin Exp Dent. 2017:9:e832-6.

15. Russell-Swetek A, West AN, Mintern JE, Jenkins J, Rodriguez-Galindo C, Ribeiro R, Zambetti GP. Identification of a novel TP53 germline mutation E285V in a rare case of paediatric adrenocortical carcinoma and choroid plexus carcinoma. J Med Genet. 2008;45:603-6.

16. Nakagaki T, Tamura M, Kobashi K, Koyama R, Fukushima H, Ohashi T, Idogawa M, Ogi K, Hiratsuka H, Tokino T, Sasaki Y. Profiling cancer-related gene mutations in oral squamous cell carcinoma from Japanese patients by targeted amplicon sequencing. Oncotarget. 2017;8:59113-22.

17. Lo lacono M, Buttigliero C, Monica V, Bollito E, Garrou D, Cappia S, Rapa I, Vignani F, Bertaglia V, Fiori C, et al. Retrospective study testing next 
generation sequencing of selected cancer-associated genes in resected prostate cancer. Oncotarget. 2016;7:14394-404.

18. Masago K, Fujita S, Muraki M, Hata A, Okuda C, Otsuka K, Kaji R, Takeshita J, Kato R, Katakami N, Hirata Y. Next-generation sequencing of tyrosine kinase inhibitor-resistant non-small-cell lung cancers in patients harboring epidermal growth factor-activating mutations. BMC Cancer. 2015;15:908.

19. Fiorentino M, Gruppioni E, Massari F, Giunchi F, Altimari A, Ciccarese C, Bimbatti D, Scarpa A, lacovelli R, Porta C, et al. Wide spetcrum mutational analysis of metastatic renal cell cancer: a retrospective next generation sequencing approach. Oncotarget. 2017;8:7328-35.

20. Naruse T, Yanamoto S, Sakamoto Y, Ikeda T, Yamada SI, Umeda M. Clinicopathological study of primary intraosseous squamous cell carcinoma of the jaw and a review of the literature. J Oral Maxillofac Surg. 2016;74: $2420-7$.

\section{Publisher's Note}

Springer Nature remains neutral with regard to jurisdictional claims in published maps and institutional affiliations.

Ready to submit your research? Choose BMC and benefit from:

- fast, convenient online submission

- thorough peer review by experienced researchers in your field

- rapid publication on acceptance

- support for research data, including large and complex data types

- gold Open Access which fosters wider collaboration and increased citations

- maximum visibility for your research: over $100 \mathrm{M}$ website views per year

At BMC, research is always in progress.

Learn more biomedcentral.com/submissions 